\title{
Profile of deaths due to burn injuries: A retrospective study of eight years in a tertiary care centre in Western Maharashtra
}

\author{
Rashid Nehal Khan ${ }^{1}$, K V Radhakrishna ${ }^{2 *}$, Ravi Rautji ${ }^{3}$, Yasho Chaturvedi ${ }^{4}$, Gautam Dhokia ${ }^{5}$ \\ ${ }^{1}$ Assistant Professor, ${ }^{2}$ Associate Professor,, Professor \& HOD, ${ }^{4,5}$ PG Resident, ${ }^{1-5}$ Dept of Forensic Medicine \& Toxicology, AFMC Pune, \\ Maharashtra, India
}

*Corresponding Author: K V Radhakrishna

Email: krashidnehal@ hotmail.com

\begin{abstract}
Introduction: In India 7 million people suffer from burn injury, out of which, 7 lakh need hospital admission and 2.4 lakh become disabled. Burn injuries have varied aetiological factors with varied demographic profile. The cause of death is in direct link to percentage and depth of burn injuries. Hence, this study was undertaken to study the profile of burn patients and come to conclusion of the aetiological factors leading to mortality in burn cases.

Aims \& Objectives: To describe the profile of burn injuries related death based on retrospective study of eight years in a tertiary care centre in Western Maharashtra, and to study the burn injuries fatalities based on age, sex, place of residence, cause of injuries body surface area affected and cause of death.

Materials \& Methods: A 8 year retrospective data of all the autopsies conducted where the cause of death was due to burns were studied as per aim and objective of study. The data from 2011 to 2018 were studied.

Results: A total of 87 cases died due to burn injuries in the period from 2011 to 2018 . Total autopsies conducted for all cases at the centre were 1976. Maximum cases were seen $(42.72 \%)$ in 16-30 years age group. $75.86 \%$ were female victims. The urban setting was involved in $37.93 \%$ and rural setting was in $66.87 \%$. The cause of death was septicemia in 68 cases, shock in 12 cases, asphyxia in 5 cases and renal failure in 2 cases. The most common percentage of burns leading to fatalities was above $60 \%$ burns. As per the cause, $75.86 \%$ cases were due to flame burns.

Conclusion: The epidemiological factors of the burn injuries are varied in different regions of world. For effective planning and preventing burn injuries, the approach has to be multi pronged like awareness, education and early treatment.
\end{abstract}

Keywords: Profile, Burns, Septicaemia.

\section{Introduction}

Man invented fire since ages. The use of fire was used for basic comforts and to sustain lives. Without fire life on earth was near impossible but it also added to risk of lives by increasing the risk of burns injuries. Fatal burns have continued to be a major public health problem in India. It is a misery which involves all strata of society and involves high risk of morbidity and mortality. Fire is present in all our homes, be it city or village. In India, about 60,000 people suffer from burns annually, more than 50,000 are treated in hospitals and about 10,000 succumb to thermal injuries. Microbial infections after burns, where a large portion of the skin is damaged, is a very serious complication that often results in the death of the patients. About $45 \%$ of the mortality in burns patients is caused by septicaemia. ${ }^{1}$

As per the data extrapolated from the information received from three major government Hospital in Delhi, approximately 1.4 lakh people die of burn injuries annually. This comes to one death every 4 minutes due to burns; however, burn injury is mostly unrecognized in our country. ${ }^{2}$

Burn injuries have varied aetiological factors with varied demographic profile. The cause of death is in direct link to percentage and depth of burn injuries. Hence, this study was undertaken to study the profile of burn patients who had reported for medicolegal autopsy and data was analysed based on the aetiology, demographic profile and cause of death. The study was aimed to suggest preventive measures after analysing the data on a 8 year retrospective study in a tertiary care centre.

\section{Aim}

To describe the profile of burn injuries related death based on retrospective study of eight years

\section{Objectives}

1. To study the burn injuries fatalities based on age, sex and place of residence.

2. To study the fatalities type, causes, body surface area affected and cause of death.

3. To suggest preventive measures.

\section{Materials and Methods \\ Study settings and population}

The study was conducted on all burn injuries brought to medicolegal postmortem centre for autopsy at a Tertiary Care Hospital in Western Maharashtra.

\section{Inclusion criteria}

All the deaths due to burn injuries brought for autopsy at the medicolegal postmortem centre of tertiary care hospital. 


\section{Exclusion criteria}

1. Decomposed bodies

2. Deaths associated with other serious life threatening traumatic injury like head injury which may have direct effect on cause of death.

\section{Sample size with justification}

A 8 year retrospective data of all the autopsies conducted where the cause of death was due to burns were studied as per aim and objective of study. The data from 2011 to 2018 were studied. A total of 1976 autopsies were conducted during the study period in the medicolegal postmortem centre. In this the 87 case were there where the cause of death was due to burns involving flame, liquid, chemical and electrical burns.

\section{Measurement and Analysis}

The postmortem report was studied and data noted as per aim and objective of study and data recorded in a profroma. Data was analysed using excel sheet and statistical calculations done.

\section{Results}

A total of 87 cases died due to burn injuries in the period from 2011 to 2018. Total autopsies of all cases conducted at the centre were 1976 . The male were $21(24.13 \%$ ) cases and females $66(75.86 \%)$. The age group showed 05 cases in 0-15years age group, 37 case in 16-30 years age group, 16 cases in 31 to 45 years age group, 17 cases in 45- 60 years age group and there were 12 cases above 60 years of age. The urban setting was involved in 33 cases and rural setting was in 54 cases. The cause of death was septicemia in 68 cases, burn shock in 12 cases, asphyxia in 5 cases, renal failure in 2 cases. The most common percentage of burns was above $60 \%$ ( 68 cases), $31 \%$ to $60 \%$ burns were seen in 17 cases and 2 cases had below $30 \%$ burns. As per the cause, 64 cases were due to flame burns, 12 cases due to falling of liquids like water and oil, 7 cases were due to chemical burns and 4 cases were due to electrical burns.

\section{Discussion}

In our present study (Table 1) the maximum fatalities are in age group 15 to 30 age group (42.52\%). In a study published in Egypt it was found that the highest percentage of the cases of burns was found in age group 0 to 10 years, the total number was 127 cases, which represented $57.3 \%$ of the total cases in year 2015 and 74 cases, which represented $46.8 \%$ of the total cases in year $2016 .^{3}$ In a study published in Karnataka ${ }^{2}$ it was found that 14-30 age group showed max burn injury cases(41.8\%) .In a study conducted at $\mathrm{Nagpur}^{4}$ it was found that the peak incidence was between age group 21 years to 30 years ie $47.1 \%$. Our findings are similar to findings to Indian study.

As per the sex distribution, the present study shows $75.86 \%$ (Table 2) are female victims. This is in consistent with a study done in North India ${ }^{5}$ which showed $63 \%$ as female victims. In a study conducted by Shankar et al in North Karnataka ${ }^{6}$ it was found that $55.83 \%$ of victims were females. All these studies show a higher female percentage of victims in cases of burns. Females are more exposed to fire as they cook on regular basis. Also the females way of dressing like dupattas and wrapped saris could also contribute to higher percentage of burn injuries in female sex.

As per place of residence in our study it was found out that $66.87 \%$ were from rural settings and $37.93 \%$ were from urban settings. (Table 3) In study conducted in North Karnataka ${ }^{6}$ it was found out that $55.42 \%$ of cases occurred in Kutcha houses in rural settings. Similar findings have been seen in study from Bombay ${ }^{7}$ and Indore. ${ }^{8}$ The reason behind is more dependence on conventional cooking methods and lack of awareness of the lethality of burn injuries in rural settings.

In our study (Table 4) the most common cause of burn deaths are flame burns $(75.86 \%)$. Other studies done in West Bengal ${ }^{9}$ showed house-hold flame was responsible for $61.45 \%$ of all burn cases. In a study in Indore it showed that flame burns were responsible for $80.3 \%$ of cases. ${ }^{10}$ In a study at Delhi most of the burn cases were of flame burn $(97.10 \%)$ and only few cases $(2.89 \%)$ were of scalds. ${ }^{11}$ The higher percentage of flame burns could be attributed to exposure to flames while cooking and also to kerosene in rural settings.

In our present study (Table 5) maximum fatalities were seen in above $60 \%$ group $(78.16 \%)$. Other studies done in Delhi ${ }^{11}$ in a tertiary care showed in $46.37 \%$ cases total body surface area of burn was between 90 to $100 \%$ followed by $80-90 \%$ in $14 \%$ cases. Palimar V et al, reported $54.9 \%$ with burns above $60 \%$ of total body surface area. ${ }^{12}$ In a study at Loni $^{13}$ in Maharashtra it was observed that more than $80 \%$ of body surface area was involved in $41.875 \%$. The findings were not consistent with the study of Usama $B^{14}$ et al 25 where $26 \%$ to $50 \%$ was most commonly affected victims. It is very certain that the deaths are in directly proportional to percentage of burns. Hence all studies with higher percentage of burns show higher mortality.

In our present study (Table 6) it shows the most common cause of death is Septicaemia $(78.16 \%)$. Other were shock in 12 cases, asphyxia in 5 cases and renal failure in 2 cases. In a study at Delhi ${ }^{11}$ it was observed that $46.85 \%$ died of shock and $53.14 \%$ victims died of septicemia . Another study reported a majority of deaths $(55 \%)$ due to septicemia as the major cause of death ${ }^{15}$. In another study on 352 patients, 16 deaths occurred and the final causes of death were septicaemic shock in 10 patients, adverse drug reaction in one patient and bleeding peptic ulcer in one patient. ${ }^{16}$

Table 1: Age Distribution

\begin{tabular}{|l|c|c|}
\hline Age group & Number of Cases & Percentage \\
\hline 0-15 years & 05 & 5.74 \\
\hline 16 -30 years & 37 & 42.52 \\
\hline 31-45 years & 16 & 18.39 \\
\hline 46-60 years & 17 & 19.54 \\
\hline Above 60 years & 12 & 13.79 \\
\hline
\end{tabular}


Table 2: Sex Distribution

\begin{tabular}{|c|c|c|c|}
\hline $\begin{array}{c}\text { No. of } \\
\text { Males }\end{array}$ & $\begin{array}{c}\text { Percentage of } \\
\text { Males }\end{array}$ & $\begin{array}{c}\text { Number of } \\
\text { Females }\end{array}$ & $\begin{array}{c}\text { Percentage of } \\
\text { Females }\end{array}$ \\
\hline 21 & 24.13 & 66 & 75.86. \\
\hline
\end{tabular}

Table 3: Place of Residence

\begin{tabular}{|l|l|l|}
\hline \multicolumn{1}{|c|}{$\begin{array}{c}\text { Place of } \\
\text { Residence }\end{array}$} & $\begin{array}{c}\text { Number of } \\
\text { Cases }\end{array}$ & $\begin{array}{c}\text { Percentage of } \\
\text { Cases }\end{array}$ \\
\hline Rural Setting & 54 & 66.87 \\
\hline Urban Setting & 33 & 37.93 \\
\hline
\end{tabular}

Table 4: Cause of Burn Injuries

\begin{tabular}{|l|l|l|}
\hline Cause of Burn Injuries & Number of Cases & Percentage \\
\hline Flame Burns & 66 & 75.86 \\
\hline Scalds & 12 & 13.79 \\
\hline Chemical Burns & 07 & 8.04 \\
\hline Electrical Burns & 02 & 2.29 \\
\hline
\end{tabular}

Table 5: Percentage of Burns

\begin{tabular}{|l|l|l|}
\hline Percentage of Burns & Number of Cases & Percentage \\
\hline Above 60 & 68 & 78.16 \\
\hline $31-60$ & 17 & 19.54 \\
\hline $0-30$ & 02 & 2.29 \\
\hline
\end{tabular}

Table 6: Cause of Death

\begin{tabular}{|l|l|l|}
\hline Cause of Death & Number of Cases & Percentage \\
\hline Septicaemia & 68 & 78.16 \\
\hline Burn Shock & 12 & 13.79 \\
\hline Asphyxia & 05 & 5.74 \\
\hline Renal Failure & 02 & 2.29 \\
\hline
\end{tabular}

\section{Conclusion}

The epidemiological factors of the burn injuries are varied in different regions of world. For effective planning and preventing burn injuries, the approach has to be multi pronged and this can largely be accomplished by taking the measures like a high sense of awareness about the lethality of burn injuries, educating people about safe cooking and taking personal preventive measures and finally early reporting of cases to higher centres to ensure effective treatment.

\section{Source of Funding: None.}

Conflict of Interest: None.

\section{References}

1. Gupta R, Kumar V, Tripathi SK. Profile of the Fatal Burn Deaths from the Varanasi Region, India. J Clin Diagn Res 2012; 2;6(4): 608-11.

2. Krishnamurthy V R, Ishwaraprasad GD, Sumana M , Samudyatha U. Pattern of burn injury admissions at a teaching hospital of Karnataka, India: A three year retrospective study . Int Surg J 2018;5(12):3930-4.

3. George SM, Nora Z. The Medicolegal Aspects Of Burn Cases Admitted To Assiut University Hospitals During Years of 2015 And 2016. J Forensic Med \& Toxicol 2017;15(1):60-75.

4. Ambade VN, Godbole HV. Study of Burn deaths in Nagpur. Burns 2000(32):902-8.

5. Mir SM, Mir MM, Rashid H,Ganai S, Ahmad T. A Study on Demographic and Clinical Profile of Burn Patients In A Tertiary Care Teaching Institute Of North India. Int $\mathrm{J} \mathrm{Med}$ Pharm Res 2016;2(10):755-7.

6. Shankar G, Naik VA, Powar R. Epidemiological study of burn patients admitted in a District Hospital of North Karnataka, India. Indian J Burns 2014;22(1):80-7.

7. Jaiswal AK, Aggarwal H, Solanki P, Lubana PS, Mathur RK, Odiya S. Epidemiological and socio-cultural study of burn patients in M. Y. Hospital, Indore, India. Indian J Plast Surg 2007:40:158-63.

8. Jha SS. Burns' mortality in Bombay. Burns 1981;8:118-22.

9. Chakraborty C, Bisoi S,Chattopadhyay D, Mishra R, Bhattacharya N, Biswas B. A Study on Demographic and Clinical Profile of Burn Patients in an Apex Institute of West Bengal. Indian J Public Health. 2010;54(1):27-9.

10. Jaiswal AK, Aggarwal H, Solanki P, Lubana PS, Mathur RK, Odiya S. Epidemiological and socio-cultural study of burn patients in M.Y.Hospital, Indore. Indian J Plastic Surg 2007;40:158-63.

11. Chaudhary BL, Yadav P, Kumar M, Rah B.Mortality Profile of Burn Injuries: A Postmortem Study in Lady Hardings Medical College, New Delhi . J Indian Acad Forensic Med 2013; 35(2):123-7.

12. Palimer V, Raghvendra Babu Y.P. Fatal burns in children. J Indian Acad Forensic Med 2009;31(2)122-4.

13. Gonnade U, Farooqui JM. Retrospective Analysis of Death Due To Burns In Rural Region. J Forensic Med Sci Law 2013;22(1).

14. Usama B. Ghaffar, Munnawar Hussain, Shameen J Rizvi :Thermal burn :An epidemiological Prospective study . $J$ Indian academic Forensic Med 2008;30(1):10-4.

15. Ramakrishnan KM, Sankar J, Venkatraman J. Profile of paediatric burns Indian experience in a tertiary care burn unit. Burns 2005; 31(3):351-3.

16. Ho WS, Ying SY, Burd A. Outcome analysis of 286 severely burned patients: retrospective study. Hong Kong Med J 2002;8(4):235-9.

How to cite this article: Khan $\mathrm{R} \mathrm{N}, \mathrm{K}$ V Radhakrishna, Rautji R, Chaturvedi Y, Dhokia G. Profile of deaths due to burn injuries: a retrospective study of eight years in a tertiary care centre in western Maharashtra. Int J Forensic Med Toxicol Sci 2019;4(4):137-9. 